\title{
Orientação à Queixa Escolar: Considerando a Dimensão Social
}

Guidance on how to deal with school problems:

Considering the social dimension

Beatriz de Paula Souza

Universidade de São Paulo

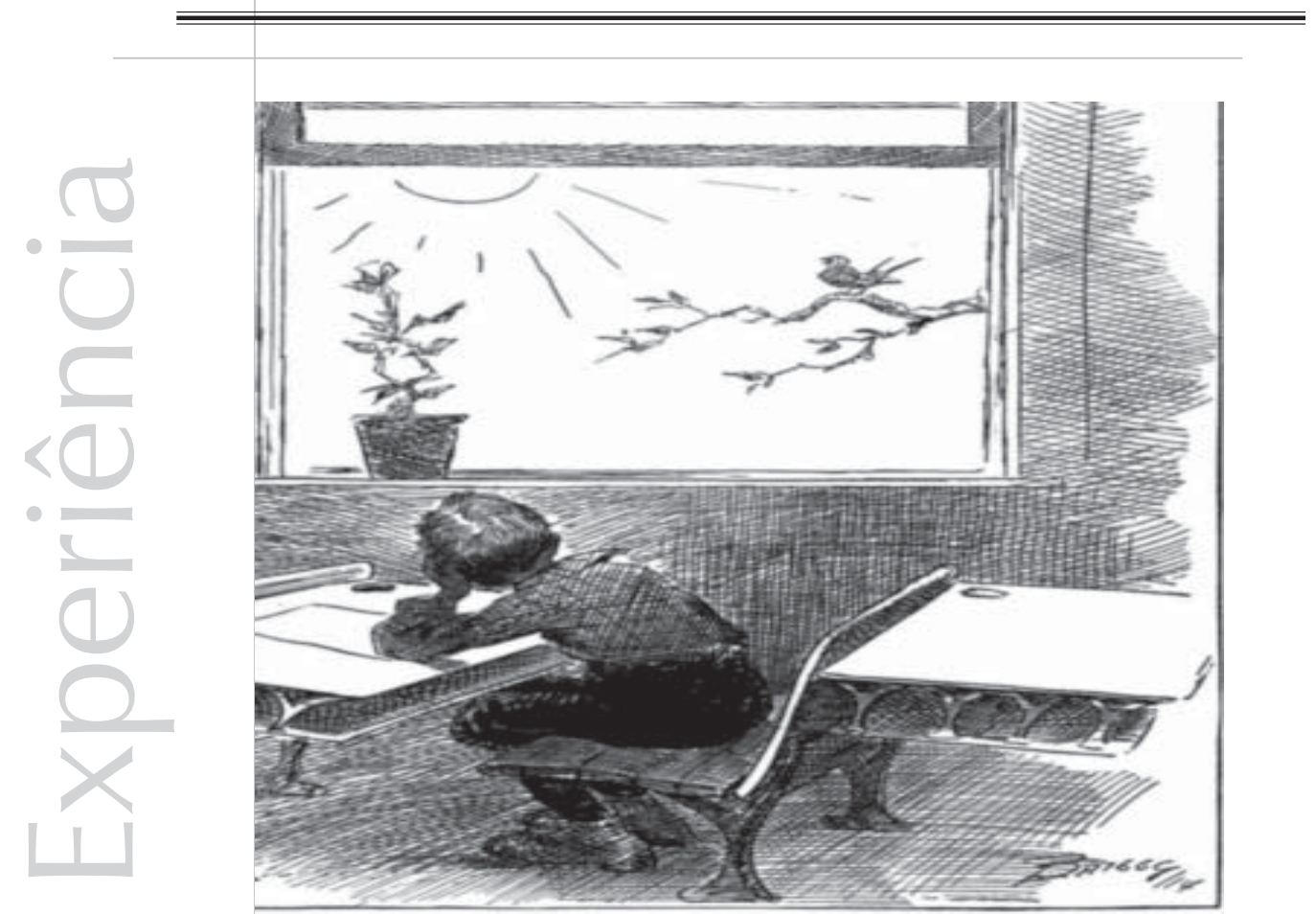


Resumo: Trata-se de uma modalidade de atendimento clínico às queixas escolares, breve e focal. Partiu-se da necessidade de desenvolver uma abordagem que superasse as dificuldades das práticas tradicionais, fundadas numa concepção abstrata de indivíduo, desconsiderando seu contexto social para além do grupo familiar e, assim, excluindo a escola da investigação e da intervenção.Nosso objetivo é conquistar uma movimentação da rede de relações na qual emerge a queixa escolar no sentido de sua superação. Essa rede tem como personagens principais, via de regra, a criança/adolescente, sua escola e sua família. Assim, nosso objeto de investigação/intervenção é essa rede e como as relações entre seus participantes se desenvolveram e se desenvolvem. Alguns princípios técnicos são: obter e problematizar as versões de cada participante, promover a circulação das informações pertinentes e identificar, mobilizar e fortalecer as potências contidas nessa rede.

Palavras-chave: queixa escolar, fracasso escolar, saúde mental, atendimento psicológico.

Abstract : This project refers to a type of brief and focused clinical counseling on how to deal with school problems. It arose from the need to develop a procedure to overcome the difficulties faced by traditional practices. These practices are based on a concept of an abstract individual, which disregards social connections beyond the family group, thereby excluding school both from investigation and intervention. Our aim is to create a movement in the network of relationships whereby school problems will come up, so as to be dealt with and overcome. Generally speaking, this network's main characters are: the child/adolescent, his/her school and his/her family. Thus the focus of our investigation/intervention is this network and how the relationships among its participants developed and continue to develop. Some basic techniques are: gather each participant's version to reach the problem area, begin circulating the relevant information and identify, move and strengthen the potentialities within this network.

key- words: school problems, school failure, mental health, psychological guidance.

A modalidade de atendimento psicológico à queixa escolar apresentada a seguir estruturouse na convergência de diversas necessidades e fundamentos teórico-práticos.

É uma das produções do Serviço de Psicologia Escolar da USP, do qual faço parte. Atuando na interface entre Psicologia e Educação, esse Serviço tem desenvolvido diversas frentes de trabalho: intervenções em escolas e outras instituições educativas, cursos para professores, participação em eventos, publicações e assessoria a grupos de educadores e trabalhadores em saúde mental preocupados com as queixas escolares, entre outras.

Psicólogos da rede pública de saúde, à procura de novos rumos no atendimento às queixas escolares, revelaram que tais queixas constituíam cerca de $75 \%$ de sua demanda infanto-juvenil. Tal cifra confirma-se na pesquisa de Marilene Proença R. de Souza (1996) junto a clínicas-escola de instituições de ensino de Psicologia da Grande
São Paulo, repetindo índices de unidades básicas e centros de saúde do Município de São Paulo (Morais, 2001), o que evidencia a prioridade que a queixa escolar deveria ter na nossa formação e nas ações da saúde.

A visão crítica que tínhamos acerca dos funcionamentos escolares cotidianos produtores de fracasso - a partir da obra de Maria Helena S. Patto, de outros autores e de nosso convívio com as escolas - levavam-nos a incentivar, apoiar e assessorar esses psicólogos, que nos procuravam em suas experiências extra-muros das unidades básicas e centros de saúde, partindo para intervir nas escolas.

No entanto, esse tipo de assessoria evidenciava uma lacuna no conjunto de ações que o Serviço desenvolvia: o atendimento às queixas escolares no âmbito da clínica. Era preciso desenvolver uma abordagem que superasse as dificuldades das práticas tradicionais, que se fundam numa concepção abstrata de indivíduo, desconsiderando 


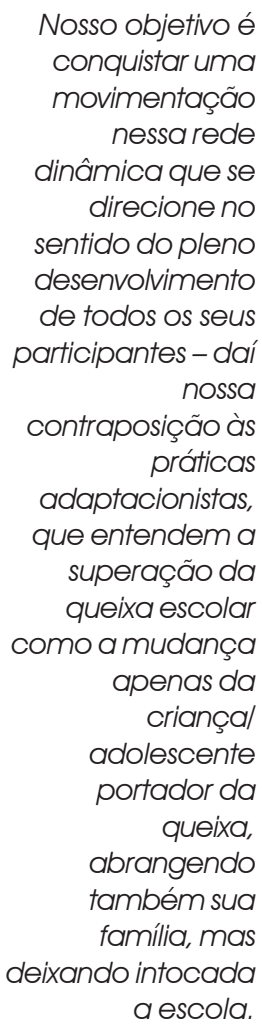

seus pertencimentos sociais, para além do grupo familiar.

Era preciso incluir a escola na investigação e na intervenção. Perguntas como: em que tipo de classe está? Quantas professoras teve este ano? Onde se senta na classe? Qual a freqüência com que ocorrem faltas de professores? Em que momento da carreira escolar emergiu a queixa em questão? precisavam ser incluídas no rol de perguntas possíveis no atendimento.

A interlocução com a escola, à semelhança da que se tem com os pais, necessitava ser introduzida.

Era preciso, ainda, ter um olhar para as camadas social e étnica a que pertenciam os envolvidos e os desdobramentos disso na vida e carreira escolares da criança ou adolescente atendido. A passagem de uma criança pobre e negra pela escola tende a guardar diferenças significativas em relação à de uma rica e branca. O estágio de conhecimento que a Psicologia e outras ciências atingiram acerca da importância dos fatores sociais na constituição das subjetividades não nos permite mais ignorá-los num atendimento psicológico.

Impulsionadas por tais necessidades, com uma demanda de atendimento de crianças e adolescentes com queixas escolares batendo às nossas portas, apoiadas em nossas referências teóricas e em nossas práticas nas intervenções nas instituições escolares e junto a educadores, partimos para desenvolver uma abordagem em atendimento psicológico a que chamamos Orientação à Queixa Escolar.

Trata-se de uma abordagem que parte de uma determinada concepção da natureza e da gênese da queixa escolar. Entende-a como aquela que tem, em seu centro, o processo de escolarização. Trata-se de um emergente de uma rede de relações que tem como personagens principais, via de regra, a criança/adolescente, sua escola e sua família. Seu cenário principal, no qual surge, é o universo escolar.
Assim, nosso objeto de investigação/intervençãoé essa rede e como as relações entre seus integrantes se desenvolvem. Considerando que um momento é construído ao longo de uma história que lhe dá sentido, conhecer e problematizar tal história incluem-se no atendimento.

Nosso objetivo é conquistar uma movimentação nessa rede dinâmica que se direcione no sentido do pleno desenvolvimento de todos os seus participantes - daí nossa contraposição às práticas adaptacionistas, que entendem a superação da queixa escolar como a mudança apenas da criança/ adolescente portador da queixa, abrangendo também sua família, mas deixando intocada a escola. Assim, uma criança que se rebela contra aulas que lhe parecem sem sentido, autoritarismo e atos de humilhação, mostrando-se agressiva e apreendendo pouco os conteúdos pedagógicos que the são impostos nessas condições, é freqüentemente considerada responsável por suas atitudes de recusa e a meta de seu atendimento é sua adaptação/submissão.

A obra de D. Winnicott e de seus seguidores nos ensina que a intervenção no ambiente - e não apenas em suas representações no universo simbólico do indivíduo - faz parte do âmbito da ação terapêutica. Assim, estruturamos nossa abordagem a partir de princípios técnicos como:

- obter e problematizar as versões de cada participante da rede (criança, família e escola);

- promover a circulação das informações pertinentes e integração ou confronto das mesmas dentro dessa rede, propiciando releituras e buscando soluções conjuntamente;

- identificar, mobilizar e fortalecer as potências contidas nessa rede, de modo a que esta passe a movimentar-se no sentido da superação da situação produtora da queixa.

Trata-se de uma abordagem breve e focal. Breve, por dois motivos essenciais. Por um lado, porque nosso objetivo não é passar a integrar essa rede 
até a superação plena da configuração na qual a queixa emergiu, mas fazê-lo apenas até a conquista de sua movimentação no sentido da superação de tal configuração; por outro, porque, como Winnicott também nos ensina em sua obra Consultas Terapêuticas (1984), nos primeiros encontros com o terapeuta, este comparece diante do paciente na condição de objeto subjetivo. Explicando rapidamente: o terapeuta tem, sim, uma existência objetiva, mas que está envolta pela subjetividade do paciente. Assim, o paciente - devidamente acolhido - tende a instituí-lo como aquele que o entende e que é capaz de ajudá-lo. Esse momento efêmero é extremamente poderoso do ponto de vista terapêutico, podendo produzir mudanças profundas se bem manejado. E é nesse tempo que operamos.

O processo todo (exceto o acompanhamento) costuma durar por volta de dois meses. Consideramo-lo focal porque centramo-nos na queixa escolar, o que não significa que nos restrinjamos apenas ao que diz respeito diretamente a ela, mesmo porque uma abordagem assim restrita não daria conta de nosso objeto. Consideramo-la um campo bastante amplo de investigação/intervenção, porém com o olhar voltado principalmente para as relações dos conteúdos emergentes com tal queixa.

Ser continente à nossa instituição como terapeutas, na condição de objeto subjetivo, não significa uma postura passiva; pelo contrário, entendemos que uma postura ativa é especialmente importante em atendimentos psicológicos às queixas escolares. Tal postura é mobilizadora dos recursos dos atendidos se assumida a partir da construção de uma relação horizontal com os mesmos. É uma relação que não os empobrece em função de um suposto saber, mas que os acompanha e compartilha saberes com eles, constituindo-os sempre como seres capazes de serem sujeitos de sua própria história.

Tal postura relaciona-se também à questão do tempo, que, no caso das queixas escolares, tem uma especificidade que não pode ser ignorada: $\mathrm{O}$ tempo escolar, o tempo do ano letivo. Fazer com que a superação da situação de fracasso aconteça dentro desses parâmetros, se essa possibilidade existir sem violentar o tempo psicológico, deve constituir-se numa meta de trabalho terapêutico, uma vez que sabemos o quanto enfrentar uma repetência ou avançar na carreira escolar sem a aquisição dos conhecimentos e competências correspondentes (falo aqui pensando na promoção automática em que se converteu a proposta de progressão continuada ou de ciclos na Educação) costuma ser uma situação que tende a dar saltos em seu potencial enlouquecedor a cada passagem de série.

A partir dos fundamentos expostos até aqui, estruturamos uma forma de atender que não é rígida, pois a consideração das singularidades faz parte essencial de nosso trabalho. Consiste nos seguintes procedimentos:

\section{Triagem de orientação}

Uma vez que somos procurados quase sempre pelos pais, é por eles que começamos nosso trabalho, entendendo que, até esse momento, são eles os demandantes. Nesse primeiro encontro, valorizamos a presença do pai, sempre que possível, dado que a tendência ainda é a presença apenas da mãe. Solicitamos que seja trazido material escolar da criança, rica fonte de informações.

Esse momento tem por objetivos:

- apresentar a modalidade de atendimento que oferecemos, de modo que os demandantes possam escolher estar ou não incluídos no processo de posse de um mínimo de informações;

- colher a versão dos pais acerca da queixa,

- investigar e pensar a demanda que se apresenta, procurando soluções - daí a denominação de Orientação;

verificar se a queixa é ou não de natureza principalmente escolar, estabelecendo prioridades 
em caso de necessidade de atendimento, verificando se o atendimento que oferecemos é ou não o mais adequado para o caso.

Com relação à investigação, não temos um roteiro de perguntas pré-fixado. As perguntas devem surgir como decorrência dos caminhos que a narrativa sugere, levando-se em conta, ainda, as concepções acerca das queixas escolares expostas no início deste texto.

Assim, quando os pais dizem que seu filho está mal-alfabetizado e não quer ir para a escola, nossas perguntas iniciais são feitas no sentido de entender melhor, com maior profundidade, o querem dizer com isso. Por exemplo: pedimos exemplos e circunstâncias em que essas manifestações da criança ocorrem. Pedimos que os pais nos tragam o histórico do filho na relação com a escola e com a alfabetização, procurando resgatar o momento e circunstâncias em que o desencontro se iniciou e se instalou.

Nunca pedimos, logo em seguida à queixa escolar, informações acerca de gravidez, amamentação, desenvolvimento neuropsicomotor, relacionamento com os pais ou constelação familiar. Essas perguntas serão feitas apenas se fizerem sentido dentro do quadro que se vai desenhando; do contrário, a mensagem subliminar que se passa aos pais é de que a queixa escolar decorre de problemas inerentes à criança e/ou a sua família.

Os pais são convidados a expressar suas hipóteses, pensar junto conosco o que está sendo trazido e possíveis saídas. Avaliamos juntos os recursos em jogo e sua potência.

Esse momento pode ser individual (no sentido de tratar de apenas um caso) ou grupal. Geralmente o temos realizado em pequenos grupos, procurando utilizar o potencial que essa forma de atendimento propicia, ou seja, procurando fazer com que as reflexões ocorram de maneira coletiva, o que tem produzido identificações emobilizações que pensar com pares - e não apenas com um especialista conquistam, facilitando o aparecimento de informações sobre recursos e outros efeitos interessantes.

Não raro, a triagem de orientação encerra o atendimento, quando, por exemplo, se conclui que a criança e/ou seus pais e/ou a escola aparentemente já estão encontrando soluções e há uma trajetória de melhora. Nesses casos, acordamos em esperar um determinado tempo para verificar se essa trajetória permanece e, caso isso não ocorra, que os pais retomem o contato conosco.

Por vezes, esse encontro é suficiente para produzir nos pais uma releitura da situação tal que eles se tranqüilizam quanto à gravidade do que está acontecendo e/ou sentem-se capazes de lidar adequada e suficientemente com isso.

O encaminhamento para outros atendimentos especializados, tais como as psicoterapias, pode ocorrer na medida em que esse caminho for se desvelando como o mais adequado ou prioritário. Ressentimo-nos, no entanto, da precariedade do sistema público de saúde, que tem profissionais de saúde mental em número absolutamente insuficiente frente às necessidades da população. Assim, encaminhar para um atendimento psicológico gratuito é, muitas vezes, lançar essa população ao abandono.

Ressentimo-nos, ainda, da falta de psicólogos clínicos que tenham um olhar para o que ocorre no cenário escolar, valorizando o oferecimento de algum suporte às escolas ou podendo ouvir o que a criança traz acerca de seu cotidiano escolar com a devida atenção.

Quando entendemos que há questões escolares importantes na configuração do quadro que se desenhou e que nossa intervenção é necessária e prioritária, o processo de atendimento tem continuidade.

\section{Encontros com as crianças ou adolescentes}

Nesses momentos, temos como objetivos:

- colher a versão da criança sobre a queixa que se tem a respeito dela; 
- propiciar a conquista e/ou valorização de sua condição de sujeito de sua própria história, que percebe, pensa e intervém;

- perceber e acolher suas necessidades, instaurando a esperança;

- oferecer acolhimento para seus sofrimentos e dificuldades, de modo que possam encontrar inscrição no universo simbólico e tornem-se pensáveis;

- favorecer a manifestação e utilização de suas capacidades e potencialidades, afetivas e cognitivas;

A criança é informada acerca da queixa que se tem dela, porém com o cuidado de não se criar obstáculos à manifestação de outras necessidades que porventura lhe sejam mais importantes. Ao longo do processo, procuramos fazer com que ela possa pensar a existência dessa queixa, expressar sua versão sobre a mesma e problematizá-la, buscando saídas.

Assim como com os pais, não temos um roteiro pré-fixado de perguntas e procedimentos. Os encontros são planejados um a um, de acordo com o que o processo sugere. Não utilizamos testes, mas procuramos investigar o que entendemos pertinente através da observação e interação com a criança dentro de uma relação de acolhimento, confiança e aposta em sua capacidade. Essas características da relação são importantes para que seu universo de potências e dificuldades possa ser captado com adequação.

Os materiais que utilizamos, além de nós mesmos, não diferem dos encontrados nas ludoterapias em geral: materiais expressivos, jogos, brinquedos, livros, etc. Temos a preocupação de poder contar com materiais tipicamente escolares (papel pautado, lápis preto, borracha, régua, etc.) e de planejar o que estará presente em cada encontro segundo a singularidade que se desvela e o que o processo sugere de rumos investigativos, de reflexão e de elaboração.
A exploração do material escolar é especialmente preciosa. Tê-lo nos encontros, apresentado pela própria criança, é uma conquista. Através dele, muitos aspectos da vida escolar emergem, tais como o jogo de fazer de conta que sabe escrever, compartilhado por alunos e professores através das cópias, as técnicas didáticas, a adequação ou não do que se ensina e se exige na escola, as necessidades e possibilidades da criança, a relação com os pais - muitas vezes revelada em bilhetes no caderno-, o capricho, o esforço, o esforço da professora em oferecer algo adequado e outros tantos aspectos.

Conquistar a produção escolar da criança em atividades com sentido e carregadas de afetividade, num ambiente acolhedor, tem revelado muitos conhecimentos onde escola e pais pensavam que não havia quase nenhum, além fazer com que a própria criança se aproprie e imprima movimento a capacidades que julgava inexistentes ou com as quais tinha uma relação penosa e envergonhada.

Em geral, o número de encontros com a criança/ adolescente é por volta de seis, um por semana. O processo pode ser individual ou grupal.

\section{Interlocução com a escola}

Esta costuma dar-se em dois momentos: no início do processo, quando solicitamos da escola um pequeno relatório, e mais ao final, quando, de posse de tal relatório, de trabalhos com pais e criança e do delineamento de perguntas e orientações que o quadro até então composto sugeriu, vamos à escola.

No processo de marcação desse encontro, procuramos garantir a presença do professor na qualidade daquele que lida diretamente com a criança no dia a dia escolar. Esse cuidado se deve à prática comum das escolas de restringir o contato à coordenação pedagógica.

É recorrente entre psicólogos a fala de que é extremamente difícil dialogar com a escola, pois os educadores são resistentes e hostis. Não compartilhamos, via de regra, essa opinião. Nossa
A criança é informada acerca da queixa que se tem dela, porém com o cuidado de não se criar obstáculos à manifestação de outras necessidades que porventura lhe sejam mais importantes. 
experiência tem confirmado reiteradamente que, uma vez que busquemos

uma relação horizontal com os educadores, em que não pressuponhamos nossa superioridade diante desses profissionais, mas apenas nossa especialidade - com suas possibilidades e limitações;

despir-nos dos freqüentes preconceitos negativos acerca dos professores, que não levam em conta as circunstâncias estressantes, precárias e desestimulantes em que geralmente desenvolvem seus trabalhos;

ouvir sua versão da queixa, fazer perguntas que ajudem a esclarecê-la e pensá-la;

perceber e valorizar seus recursos e esforços e

- levar informações e sugestões que possam contribuir para a criação de sentidos e caminhos em seu trabalho,

costumamos encontrar receptividade. O olhar para a criança e para seus pais pode mudar e a possibilidade de fortalecer e/ou mobilizar os recursos escolares surge, nem sempre, naturalmente. Muitos são os casos em que o contato com a escola frustra, o que não deve, no entanto, paralisar-nos ou à criança e a seus pais.

O contato com a escola no espaço da mesma tem-se mostrado importante, pois revela aspectos do ambiente que uma conversa por telefone ou no local de atendimento não revelaria. Assim, podemos perceber que se trata de um ambiente opressor ou agradável, se vidros e paredes estão ou não intactos e cuidados, se há ou não crianças fora das classes, se se ouvem gritos de professores, se os compromissos marcados são valorizados e outros aspectos da vida escolar. É possível perceber o entorno da escola, o aspecto das moradias, a presença de policiais, igrejas ou música.

Geralmente esse encontro é único. Investigação, discussão de caso e busca de soluções acontecem de maneira integrada. Porém, se avaliamos ser necessário, há casos em que um novo encontro acontece.

\section{Entrevistas de fechamento}

Podem ser realizadas com a criança/adolescente e pais em separado, ou ainda com a criança/ adolescente em separado e depois junto com os pais. Vale ressaltar que podem ter ocorrido outros contatos com os pais em momentos anteriores do processo, na medida em que tenha sido necessário.

Objetiva-se construir uma releitura do caso à luz do que o processo de trabalho pôde trazer de novas informações, visões e perspectivas. Avaliase o processo de orientação e seus efeitos e procura-se pensar como os diversos envolvidos podem estar mobilizando-se no sentido da superação da situação inicial.

Combina-se um novo contato dentro de um tempo que costuma girar em torno de dois meses, sem contar o período de férias escolares.

\section{Acompanhamento}

Esse procedimento ainda é relativamente novo e ainda não temos dados sistemáticos acerca do mesmo. Consistiu, até o momento, em um novo contato com os pais e/ou com a escola após um período de cerca de dois meses do fechamento do processo de orientação à queixa escolar. Planejamos aperfeiçoá-lo, procurando colher as versões de todos os principais envolvidos: pais, escola e a própria criança/adolescente."

O acompanhamento decorre do fato de que as camadas populares carecem, muitas vezes, de informações e de ajuda para enfrentar meandros e entraves burocráticos que, por vezes, inviabilizam o acesso a recursos procurados, muitos dos quais são seu direito. Decorre, ainda, de nossa necessidade de colher dados acerca da efetividade ou não de nosso trabalho no que tange à efetiva mudança de rumos nas queixas escolares a que atendemos. Nesse sentido, nossa experiência encontra-se ainda em seus estágios iniciais, mas temos sinalizações bastante positivas. 
Em onze, de quinze casos acompanhados, os responsáveis por crianças/adolescentes atendidos referiram-se a tal atendimento como um ponto de inflexão claro numa carreira escolar e pessoal que, antes, rumava ao fracasso.

\section{Considerações finais}

Há quatro anos realizamos levantamentos anuais acerca do que realizamos que têm nos revelado alguns dados de interesse. Um deles é que, em 2004, nosso índice de desistência foi de menos de $0,5 \%$ dos atendidos. A pesquisa de Souza (op.cit.) encontrou um índice de desistência de cerca de $40 \%$ apenas após a primeira entrevista, em clínicas-escola. Temos, então, um dado que nos sinaliza estarmos construindo um atendimento que atende de maneira mais satisfatória as necessidades daqueles que procuram um atendimento psicológico para seus filhos com dificuldades em seu processo de escolarização.

A comparação é possível porque a mesma pesquisa revelou que cerca de $75 \%$ da demanda infanto-juvenil de tais clínicas é de queixas escolares - o que, aliás, é o mesmo índice encontrado em unidades básicas e centros de saúde do Município de São Paulo ( Morais, op.cit.) . Além disso, há uma parcela de cerca de $10 \%$ de nossa demanda que se revela de natureza principalmente não-escolar.

Nossos levantamentos revelam, mais uma vez, o peso das políticas educacionais na geração das queixas escolares. Entendemos que a demanda crescente de atendimento a crianças de 11-12 anos que não estão alfabetizadas, ou o estão muito precariamente, guarda relação direta com a implantação de forma questionável dos ciclos na Educação. Por outro lado, vemos crescer a demanda de crianças em idade pré-escolar com queixa de não estarem se alfabetizando, uma conseqüência funesta do caráter obrigatório que a alfabetização, nesse período da vida escolar, vem assumindo.

Novamente constatamos a impossibilidade de pensar a queixa escolar isolada de seus atravessamentos sociais se pretendemos dar conta desse objeto de conhecimento e intervenção.

Chama-nos, ainda, a atenção, o fato de que em apenas $44 \%$ dos casos em que fomos procurados ${ }^{1}$ entendemos que o processo de Orientação à Queixa Escolar não era suficiente ou adequado e consideramos necessário o encaminhamento da criança ou jovem e/ou de um ou mais familiares para atendimentos psicológicos de médio e longo prazo e/ou outros trabalhos de especialistas. Em clínicas-escola, o índice de casos em que se considera o atendimento na triagem e no psicodiagnóstico insuficientes, necessitando de encaminhamentos como os citados acima, é de $100 \%{ }^{2}$ (Souza, op.cit.). Lembramos, mais uma vez, que esta comparação é cabível, em função das queixas escolares representarem cerca de $75 \%$ da demanda infanto-juvenil de tais clínicas. Será possível que todos que procuram um psicólogo por conta de questões escolares necessitem de cuidados especializados que vão além de um atendimento psicológico breve ou até de um pensar que pode acontecer em um encontro único com um psicólogo atento à natureza escolar de tais questões?
1 Consideramos aqui todos os casos com que tivemos no mínimo um contato direto. Não consideramos os que apenas preencheram ficha de inscrição.

2 Não estão considerados os casos em que a autora não pôde, pelas informaçóes constantes nos prontuários pesquisados, identificar a continuidade ou conclusão dos mesmos. Isto ocorreuem $19 \%$ das vezes.
Beatriz de Paula Souza

Psicóloga do Instituto de Psicologia da - Universidade de São Paulo. Mestre em Psicologia

R. Dr. Manoel Maria Tourinho, 701 - Pacaembu São Paulo, SP CEP 01236-000 Fone e fax: (11) 3873.7229 E-mail:biapsico@uol.com.br
Recebido 14/07/05 Aprovado 10/03/06

MORAIS, M.L.S. Fórum de Saúde Mental. Morais, M.L.S. e Souza, B.P. (org.). Saúde e Educação: muito prazer! São Paulo: Casa do Psicólogo, 2001, pp. 69-88.

SOUZA, M.P.R. A Queixa Escolar e a Formação do Psicólogo. Tese de Doutorado em Psicologia. Instituto de Psicologia da Universidade de São Paulo, São Paulo, 1996.

WINNICOTT, D. Consultas Terapêuticas. Rio de Janeiro: Imago, 1984.
Referências 